\title{
The relationship between serum adiponectin and prognosis in patients with heart failure
}

\author{
Sokhanvar $\mathrm{S}^{1}$, Sheykhi $\mathrm{M}^{2}$, Mazlomzade $\mathrm{S}^{3}$, Taran $\mathrm{L}^{4}$, Golmohammadi $\mathrm{Z}^{5}$ \\ Ayatollah Mosavi Cardiology Department, Medical Science University, Zanjan, Iran. Rozag2001@yahoo.com
}

\begin{abstract}
Background: The role of adiponectin in the development of cardiac disease remains less clear than in metabolic disorders. While some studies indicated that low adiponectin levels were associated with cardiovascular disease, not all studies have been able to show such association. Adiponectin levels may influence the development of chronic heart failure, but the epidemiological data are somewhat complex. Thus, the aim of this study was a survey of relationship between serum Adiponectin and prognosis of patients with heart failure in Iran. Methods and materials: In this cohort study, we evaluated 96 chronic heart failure patients. Patients with systolic dysfunction that was defined as left ventricular Ejection Fraction (EF) $\leq 40 \%$ or had a history of heart failure were included in the study. At the baseline visit, all patients were examined by a physician and the following information was obtained: medical history, physical examination, New York Heart Association (NYHA) classification. After the first evaluation, analyses of adiponectin, Pro BNP, creatinine and uric acid were performed. Then the patients were followed up for a median of 12 months.

Results: There was a significant relationship between the mean adiponectin and Pro BNP levels and the ejection fraction ( $p=0.003$ and $p=0.003$ respectively). Higher levels of adiponectin and Pro BNP were associated with a lower ejection fraction and there were no such associations between creatinine and uric acid levels. There was a significant association between the functional capacity as assessed by NYHA class and the mean of adiponectin and uric acid, these means that higher levels of adiponectin and uric acid were associated with a higher functional class in patients with CHF ( $p=0.03$ and $p=0.04$ respectively). During a 12 month follow-up, 22 (22.9 $\%)$ patients died. In subjects who died, the baseline mean plasma adiponectin and Pro BNP levels were higher compared to those who were alive at the follow-up and these difference were statistically significant $(19 \pm 7.4$ vs. $15.8 \pm 8 \mathrm{ng} / \mathrm{ml}$ and $9520 \pm 10249$ vs. $3172 \pm 4628 \mathrm{ng} / \mathrm{L} \mathrm{p}=0.000$ ).

Conclusion: The present study demonstrated that the plasma adiponectin level increased according to the severity of heart failure and also there was such relationship between Pro BNP and heart failure (Tab. 3, Ref. 35). Full Text in PDF www.elis.sk.

Key words: adiponectin, prognosis, heart failure, Iran.
\end{abstract}

Chronic heart failure (CHF) is a major cause of death and disability. Mortality rates approach $20 \%$ per year despite current medical therapy (1).

Obesity is a known risk factor for cardiovascular disease and for the development of chronic heart failure (CHF) (2). However, recent data suggested that high body mass index (BMI) was associated with a more favorable prognosis in patients with established CHF (3-6).

${ }^{1}$ Ayatollah Mosavi Cardiology Department, Medical Science University, Zanjan, Iran, ${ }^{2}$ Cardiology Department, Medical Science University ,Zanjan, Iran, ${ }^{3}$ Epidemiology Department, Medical Science University, Zanjan, Iran, ${ }^{4}$ Ayatollah Mosavi Cardiology Department, Medical Science University, Zanjan, Iran, and ${ }^{5}$ Cardiovascular Research Center, Medical Science University, Tabriz, Iran

Address for correspondence: Z. Golmohammadi, Cardiovascular Research Center, Medical Science University, Tabriz, Iran Phone: +98.9143068423, Fax: +98.4113373919

Acknowledgments: This study was supported by a research grant from the Zanjan Medical University and all author thank to vice-chancellor for research
Adipose tissue secretes a variety of biologically active molecules, including cytokines, growth factors and complement factors, into the systemic circulation (7-12).

Adiponectin is a 244 amino acid protein and the most abundant adipocytokine in adipose tissue (13-14). Plasma adiponectin concentrations are extremely high in healthy subjects and vary widely in several pathological states; for example, they decrease in obesity, diabetes mellitus, hypertension and other atherosclerotic disorders (15-23).

Several features make adiponectin an attractive marker for cardiovascular risk. For example, plasma concentrations show little circadian variability, does not depend on fasting status, and shosw only a limited in-person variation over time (24-26). In addition, because adiponectin circulates in relatively high concentrations in plasma, measurement of adiponectin needs only a limited amount of blood.

It is well known that various hormones, such as arginine vasopressin, cathecholamines and the reninangiotensin- aldosterone system, increase in concert with the severity of heart failure and they may be involved in the pathogenesis of heart failure. Also it 
is well-known that brain natriuretic peptide (BNP) increases with the severity of left ventricular dysfunction, and high values of BNP are associated with poor prognosis (27).

The role of adiponectin in the development of cardiac disease remains less clear than in metabolic disorders. While some studies indicated that low adiponectin levels were associated with cardiovascular disease, not all studies have been able to show such association. For example, it has been reported that plasma adiponectin concentrations were lower in patients with clinical manifestations of coronary artery disease than in age and BMI-adjusted control subjects independent of other risk factors (28-30). High plasma adiponectin levels were associated with a lower risk of myocardial infarction in men (31). Collectively, these studies suggested that hypoadiponectinemia was associated with the development of cardiovascular diseases that are prevalent in obese individuals.

Finally, adiponectin levels may influence the development of chronic heart failure, but the epidemiological data are somewhat complex. Therefore, future studies should examine adiponectin levels in patients with stable heart failure.

\section{Methods and materials}

In this cohort study, we evaluated 96 chronic heart failure patients that referred to Shahid Beheshti and Vliasr hospitals in Zanjan since 2007 until 2009. Patients with systolic dysfunction that was defined as left ventricular Ejection Fraction (EF) $\leq 40 \%$ by echocardiography (HDI 3500) or had a history of heart failure were included in the study. At the baseline visit, all patients were examined by a physician and the following information was obtained: medical history, physical examination, New York Heart Association (NYHA) classification and the patients were divided into the four groups. Class I (Mild), no limitation of physical activity. Ordinary physical activity does not cause undue fatigue, palpitation, or dyspnea (shortness of breath). Class II (Mild), slight limitation of physical activity. Comfortable at rest, but ordinary physical activity results in fatigue, palpitation, or dyspnea. Class III (Moderate), marked limitation of physical activity. Comfortable at rest, but less than ordinary activity causes fatigue, palpitation, or dyspnea. Class IV (Severe), unable to carry out physical activity without discomfort. Symptoms of cardiac insufficiency present at rest. If any physical activity is undertaken, discomfort is increased. All data were collected in questioners. Then patients were followed up for the median of 12 months. None of the participants was lost during the follow-up. The patients included in this study have been followed up with respect to mortality status and changes in functional capacity and frequency of hospital admission. All patients with renal failure with creatinine $\geq 3 \mathrm{mg} / \mathrm{dl}$ were excluded from this study. BMI (Body Mass Index) categories by the World Health Organization was used for classification, so patients with $\mathrm{BMI}<25 \mathrm{~kg} / \mathrm{m}^{2}$ were considered normal weight and patients with BMI $25-29.9 \mathrm{~kg} / \mathrm{m}^{2}$ were considered over weight.

\section{Laboratory measurements}

After a minimum 8-hour overnight fast, venous blood was drawn into EDTA tubes and centrifuged at $4{ }^{\circ} \mathrm{C}$ and plasma was frozen at $-70{ }^{\circ} \mathrm{C}$ until analyses of adiponectin, Pro BNP, creatinine and uric acid were performed.

Adiponectin was measured by ELISA (Enzyme Linked Immuno Sorbent Assay) method by Biovendor Co. Germany kits where the assay sensitivity (detection limit $0.15 \mathrm{ng} / \mathrm{ml}$ ) and specifity was $100 \%$ and the intra-assay and inter-assay reproducibility were $(4.2-6.7 \%)$ and $(7.6-9.5 \%)$ respectively.

Pro BNP was measured by ECLIA (Electro Chemiluminescence Immun) method by Germany Elec sys 2010 Roche. The kit assay was sensitive (detection limit $5 \mathrm{pg} / \mathrm{ml}$ ) and the inter-assay reproducibility was $7.2 \%$.

Uric acid and creatinine were measured by XL-300 biochemistry (Erba Co. Germany).

\section{Statistical analysis}

All values were expressed as the mean \pm one SD. Continuous variable was analyzed by the one-way ANOVA or the KruskalWallis test to compare the difference among the four groups. Comparisons between patient groups were performed with the independent T samples test and the Mann-Whitney U test, as appropriate. All values were 2 tailed and the probability value $<0.05$ was considered statistically significant. The statistical software package SPSS version 14 was used for all analyses.

The study was approved by the local ethics committee of the Zanjan medical university and all patients signed a written informed consent.

Tab. 1. Demographic data of 96 patients with CHF.

\begin{tabular}{lc}
\hline Characteristics & $\mathrm{n}(\%)$ or mean \pm SD \\
\hline Male & $55(57.3)$ \\
Age & $62 \pm 8$ \\
Underlying disease & \\
CAD & $57(59.3)$ \\
HTN & $11(11.4)$ \\
VHD & $22(22.9)$ \\
Others & $6(6.2)$ \\
Ejection fraction & \\
$\quad \leq 24 \%$ & $27(28.1)$ \\
25-29\% & $33(34.3)$ \\
$30-34 \%$ & $19(19.8)$ \\
$\quad \geq 35 \%$ & $17(17.7)$ \\
Functional class before 12 month & \\
I & $23(23.9)$ \\
II & $35(36.4)$ \\
III & $23(23.9)$ \\
IV & $15(15.6)$ \\
Functional class after 12 month & \\
I & $34(35.4)$ \\
II & $23(23.9)$ \\
III & $16(16.6)$ \\
IV & $23(23.9)$ \\
Weight $(\mathrm{kg})$ & $64.5 \pm 11.1$ \\
Height $(\mathrm{cm})$ & $161.7 \pm 11.1$ \\
BMI $(\mathrm{kg} / \mathrm{m} 2)$ & $24.4 \pm 2.6$ \\
Pro BNP ng/L & $4627 \pm 6846$ \\
Adiponectin ng/ml & $16.5 \pm 8$ \\
Creatinine mg/dl & $1.54 \pm 1$ \\
Uric acid mg/dl & $6.6 \pm 1.9$ \\
\hline & \\
\hline
\end{tabular}




\section{Results}

Totally 96 patients (55 male and 41 female) were enrolled in the study. All demographic data are shown in the Table 1.

There was a significant relationship between the mean adiponectin and Pro BNP levels and the ejection fraction $(\mathrm{p}=0.003$ and $\mathrm{p}=0.003$ respectively). Higher levels of adiponectin and Pro BNP were associated with a lower ejection fraction (Tab. 2) and there were no such associations between creatinine and uric acid levels.

There was a significant association between the functional capacity as assessed by NYHA class and the mean of adiponectin and uric acid, these means that higher levels of adiponectin and uric acid were associated with a higher functional class in patients with $\mathrm{CHF}$ ( $\mathrm{p}=0.03$ and $\mathrm{p}=0.04$ respectively). The demographic data demonstrated that there was no relation between different age groups and the mean of adiponectin and Pro BNP and creatinine and uric. There was no association between these parameters and frequencies of hospital admission. Subsequently, the relation between plasma levels of adiponectin and BMI was examined and there was no association between the two parameters.

Adiponectin levels in the non-ischemic group were higher than in the ischemic group and this difference was statistically significant $(\mathrm{p}=0.001)$. During the 12 month follow-up, $22(22.9 \%)$ patients died. In subjects who died, the baseline mean plasma adiponectin and Pro BNP levels were higher compared to those who were alive at the follow-up and these difference were statistically significant (19 $\pm 7.4 \mathrm{vs} 15.8 \pm 8 \mathrm{ng} / \mathrm{ml}$ and $9520 \pm 10249 \mathrm{vs} 3172 \pm 4628$ $\mathrm{ng} / \mathrm{L} \mathrm{p}=0.000$ ) (Tab. 3).

\section{Discussion}

The present study demonstrated that the plasma adiponectin level increased according to the severity of heart failure and that there was such relationship between Pro BNP and heart failure. Recently Kistorp et al reported that the plasma level of adiponectin and N-terminal Pro BNP was a risk marker of CHF severity and predictor of mortality (32), what was consistent with our study. There was no association between adiponectin and Pro BNP and frequency of hospital admission. Pocock SJ et al showed that there was 21 predictor variables for cardiovascular death and heart failure hospitalization, the three most powerful predictors were higher age (beginning $>60$ years), diabetes and lower left ventricular ejection fraction beginning $<45 \%)(33)$. Adiponectin may influence the development of CHF, but the epidemiological data are scarce. Plasma levels of adiponectin are decreased in patients with

Tab. 2. Association between the mean adiponectin, Pro BNP, uric acid, creatinine and ejection fraction (EF)

\begin{tabular}{lcccc}
\hline Parameters & EF group & $\mathrm{N}$ & Mean $\pm \mathrm{SD}$ & $\mathrm{Pv}$ \\
\hline Adiponectin & $\leq 24 \%$ & 27 & $18.11 \pm 1.71$ & 0.003 ( One-Way ANOVA) \\
$\mathrm{Ng} / \mathrm{ml}$ & $25-29 \%$ & 33 & $17.54 \pm 7.57$ & 0.001 (Kruskal-Wallis Test) \\
& $30-34 \%$ & 19 & $18.38 \pm 8.96$ & \\
Creatinine & $\geq 35 \%$ & 27 & $10.17 \pm 5.12$ & 0.755 ( One-Way ANOVA) \\
$\mathrm{Mg} / \mathrm{dl}$ & $\leq 24 \%$ & 33 & $1.66 \pm 1.04$ & 0.628 (Kruskal-Wallis Test) \\
& $25-29 \%$ & 19 & $1.51 \pm 1.00$ & \\
Uric acid & $30-34 \%$ & 17 & $1.60 \pm 1.53$ & 0.469 ( One-Way ANOVA) \\
$\mathrm{Mg} / \mathrm{dl}$ & $\geq 35 \%$ & 27 & $6.63 \pm 2.29$ & 0.386 (Kruskal-Wallis Test) \\
& $\leq 24 \%$ & 33 & $6.94 \pm 1.62$ & \\
$\mathrm{Pro} \mathrm{BNP}$ & $25-29 \%$ & 19 & $6.57 \pm 2.42$ & 0.003 ( One-Way ANOVA) \\
$\mathrm{Ng} / \mathrm{L}$ & $30-34 \%$ & $5.99 \pm 1.56$ & 0.021 (Kruskal-Wallis Test) \\
& $\geq 35 \%$ & 27 & $8659.64 \pm 10241.41$ & \\
\hline
\end{tabular}

Tab. 3. Association between the mean adiponectin, Pro BNP, uric acid, creatinine and mortality.

\begin{tabular}{|c|c|c|c|c|}
\hline Parameters & Status & $\mathrm{N}$ & Mean $\pm \mathrm{SD}$ & $\mathrm{Pv}$ \\
\hline Adiponectin & died & 22 & $19.09 \pm 7.44$ & 0.09 (Independent T Samples Test) \\
\hline $\mathrm{Ng} / \mathrm{ml}$ & alive & 74 & $15.81 \pm 8.07$ & 0.03 (Mann-Whitney U) \\
\hline Creatinine & died & 22 & $1.51 \pm 0.66$ & 0.88 (Independent T Samples Test) \\
\hline $\mathrm{Mg} / \mathrm{dl}$ & alive & 74 & $1.55 \pm 1.17$ & 0.55 (Mann-Whitney U) \\
\hline Uric acid & died & 22 & $6.38 \pm 1.51$ & 0.53 (Independent T Samples Test) \\
\hline Pro BNP & died & 22 & $9520.46 \pm 10249.36$ & 0.000 (Independent T Samples Test) \\
\hline \multirow[t]{2}{*}{$\mathrm{Ng} / \mathrm{L}$} & alive & 74 & $3172.19 \pm 4628.77$ & 0.001 (Mann-Whitney U) \\
\hline & total & 96 & & \\
\hline
\end{tabular}


ischemic heart disease but increased in patients with heart failure. The source of increased adiponectin levels in patients with CHF remains unknown. Takano $\mathrm{H}$ et al showed that adiponectin levels were significantly higher in patients with either non-ischemic CHF or ischemic CHF than controls; the levels were similar between patients with non-ischemic CHF and those with ischemic CHF (34), but in our study, adiponectin levels in the non-ischemic group were higher than in the ischemic group. In our study, adiponectin and Pro BNP levels were very useful in survival determination. This means that the mean Pro BNP and adiponectin levels were different between alive and dead patients and this difference was statistically significant. This finding is in accordance with previous reports on survival analyses, which demonstrated that high adiponectin levels were associated with an increased mortality risk and patients with circulating adiponectin levels in the 2 upper tertiles had a 3 -fold increased risk of mortality compared to those in the lowest tertiles (32).

This finding could be counterintuitive, because adiponectin has been described to have anti inflammatory and anti atherogenic properties. Epson $\mathrm{H}$ et al showed that adiponectin levels were significantly increased in heart failure patients older than 70 years as compared to control group (35), but our study did not show such association. However, in their study, there were higher adiponectin levels in the non-ischemic heart failure as compared to those with ischemic causes and there was a strong trend of higher adiponectin levels in those who died as compared to those who survived and all of these were consistent with our results.

There are some limitations in our study: first; we did not measure changes in weight or Pro BNP and adiponectin levels during the follow up. Second; we had a small sample size and also small number of deaths. Third; we did not have cut off point for adiponectin and Pro BNP in our healthy population.

However, this is the first study that evaluated the relationship between adiponectin and prognosis of heart failure in our country and we suggested a larger study with a longer follow-up period.

\section{References}

1. American Heart Association. Heart Disease and Stroke Statistics 2003 Update. Dallas, Texas: American Heart Association; 2003.

2. Kenchaiah S, Evans JC, Levy D, Wilson PW, Benjamin EJ, Larson MG, Kannel WB, Vasan RS. Obesity and the risk of heart failure. New Engl J Med 2002; 347: 305-313.

3. Lavie CJ, Osman AF, Milani RV, Mehra MR. Body composition and prognosis in chronic systolic heart failure: the obesity paradox. Am J Cardiol 2003; 91: 89-894.

4. Horwich TB, Fonarow GC. The impact of obesity on survival in patients with heart failure. Heart Fail Monit 2002; 3: 8-14.

5. Mehra MR, Uber PA, Park MH, Scott RL, Ventura HO, Harris BC, Frohlich ED. Obesity and suppressed B-type natriuretic peptide levels in heart failure. J Am Coll Cardiol 2004; 43: 1590-1595.

6. Davos CH, Doehner W, Rauchhaus M, Cicoira M, Francis DP, Coats AJ, Clark AL, Anker SD. Body mass and survival in patients with chronic heart failure without cachexia: the importance of obesity. J Card Fail 2003; 91: 29-35.
7. Maeda K, Okubo K, Shimomura I, Mizuno K, Matsuzawa Y, Matsubara K. Analysis of an expression profile of genes in the human adipose tissue. Gene 1997; 190: 227-235.

8. Spiegelman BM, Choy L, Hotamisligil GS, Graves RA, Tontonoz P. Regulation of adipocyte gene expression in differentiation and syndromes of obesity/diabetes. J Biol Chem 1993; 268: 6823-6826.

9. Zhang Y, Proenca R, Maffei M, Barone M, Leopold L, Friedman JM. Positional cloning of the mouse obese gene and its human homologue. Nature 1994; 372: 425-432.

10. Shimomura I, Funahashi T, Takahashi M, Maeda K, Kotani K, Nakamura T et al. Enhanced expression of PAI-1 in visceral fat: Possible contribution to vascular disease in obesity. Nat Med 1996; 2: 800-803.

11. Matsumoto S, Kishida K, Shimomura I, Maeda N, Nagaretani $\mathbf{H}$, Matsuda $\mathbf{M}$ et al. Increased plasma HB-EGF associated with obesity and coronary artery disease. Biochem Biophys Res Commun 2002; 292: 781-786.

12. Hotamisligil GS, Shargill NS, Spiegelman BM. Adipose expression of tumor necrosis factor-alpha: Direct role in obesity-linked insulin resistance. Science 1993; 259: 87-91.

13. Maeda K, Okubo K, Shimomura I, Funahashi T, Matsuzawa Y, Matsubara K. cDNA cloning and expression of a novel adipose collagen - like factor, apM1 (adipose most abundant gene transcript 1). Biochem Biophys Res Commun 1996; 221: 286-289.

14. Scherer PE, William S, Fogliano M, Baldini G, Lodish HF. A novel serum protein similar to C1q, produced exclusively in adipocytes. J Biol Chem 1995; 270: 26746-26749.

15. Arita Y, Kihara S, Ouchi N, Takahashi M, Maeda K, Miyagawa J et al. Paradoxical decrease of an adipose-specific protein, adiponectin, in obesity. Biochem Biophys Res Commun 1999; 257: 79-83.

16. Hotta K, Funahashi T, Arita Y, Takahashi M, Matsuda M, Okamoto $\mathrm{Y}$ et al. Plasma concentrations of a novel, adipose-specific protein adiponectin, in type 2 diabetic patients. Arterioscler Thromb Vasc Biol 2000; 20: 1595-1599.

17. Kumada M, Kihara S, Sumitsuji S, Kawamoto T, Matsumoto S, Ouchi N et al; Osaka CAD Study Group. Coronary artery disease. Association of hypoadiponectinemia with coronary artery disease in men. Arterioscler Thromb Vasc Biol 2003; 23: 85-89.

18. Pichon T, Girman CJ, Hotamisligil GS, Rifai N, Hu FB, Rimm EB. Plasma adiponectin levels and risk of myocardial infarction in men. J Amer Med Ass 2004; 291: 1730-1737.

19. Kawano T, Saito T, Yasu T, Saito T, Nakamura T, Namai K et al. Close association of hypoadiponectinemia with arteriosclerosis obliterans and ischemic heart disease. Metabolism 2005; 54: 653-656.

20. Iwashima Y, Katsuya T, Ishikawa K, Ouchi N, Ohishi M, Sugimoto $\mathbf{K}$ et al. Hypoadiponectinemia is an independent risk factor for hypertension. Hypertension 2004; 43: 1318-1323.

21. Hongo SJ, Seo HS, Rha SW, Oh DJ, Kwon JA, Lee KN et al. Decrease in plasma adiponectin concentrations in patients with varian angina pectroris. Circulat J 2006; 70: 414-418.

22. Maruyoshi H, Kojima S, Otsuka F, Funahashi T, Kaikita K, Sugiyama $\mathbf{S}$ et al. Hypoadiponectinemia is associated with coronary artery spasm in men. Circulat J 2005; 69: 1154-156.

23. Ryo M, Nakamura T, Kihara S, Kumada M, Shibazaki S, Takahashi $\mathbf{M}$ et al. Adiponectin as a biomarker of the metabolic syndrome. Circulat J 2004; 68: 975-981. 
24. Gavrila A, Peng CK, Chan JL, Mietus JE, Goldberger AL, Mantzoros CS. Diurnal and ultradian dynamics of serum adiponectin in healthy men: comparison with leptin, circulating soluble leptin receptor, and cortisol patterns. J Clin Endocrinol Metab 2003; 88: 2838-2843.

25. Hotta K, Funahashi T, Arita Y, Takahashi M, Matsuda M, Okamoto $\mathrm{Y}$ et al. Plasma concentrations of a novel, adipose-specific protein, adiponectin, in type 2 diabetic patients. Arterioscler Thromb Vasc Biol 2000; 20: 1595-1599.

26. Pischon T, Hotamisligil GS, Rimm EB. Adiponectin: stability in plasma over 36 hours and within-person variation over 1 year. Clin Chem 2003; 49: 650-652.

27. Tsutamoto T, Wada A, Maeda K, Hisanaga T, Maeda Y, Fukai D et al. Attenuation of compensation of endogenous cardiac natriuretic peptide system in chronic heart failure: Prognostic role of plasma brain natriuretic peptide concentration in patients with chronic symptomatic left ventricular dysfunction. Circulation 1997; 96: 509-516.

28. Ouchi N, Kihara S, Arita Y, Maeda K, Kuriyama H, Okamoto Y et al. Novel modulator for endothelial adhesion molecules: adipocytederived plasma protein adiponectin. Circulation 1999; 100: 2473-2476.

29. Kumada M, Kihara S, Sumitsuji S, Kawamoto T, Matsumoto S, Ouchi $\mathbf{N}$ et al. Association of hypoadiponectinemia with coronary artery disease in men. Arterioscler Thromb Vasc Biol 2003; 23: 85-89.
30. Nakamura Y, Shimada K, Fukuda D, Shimada Y, Ehara S, Hirose $\mathbf{M}$ et al. Implications of plasma concentrations of adiponectin in patients with coronary artery disease. Heart 2004; 90: 528-533.

31. Pischon T, Girman CJ, Hotamisligil GS, Rifai N, Hu FB, Rimm EB. Plasma adiponectin levels and risk of myocardial infarction in men. J Amer Med Ass 2004; 291: 1730-1737.

32. Kistorp C, Faber J, Galatius S, Gustafsson F, Frystyk J, Flyvbjerg A et al. Plasma adiponectin, body mass index, and mortality in patients with chronic heart failure. Circulation 2005; 112: 1756-1762.

33. Pocock SJ, Wang D, Pfeffer MA, Yusuf S, McMurray JJV, Swedberg KB, Ostergren J, Michelson EL, Pieper KS, Granger CB. Predictors of mortality and morbidity in patients with chronic heart failure. Eur Heart J 2006; 27: 65-75.

34. Takano H, Obata JE, Kodama Y, Kitta Y, Nakamura T, Mende A, Kawabata K, Saito Y, Fujioka D, Kobayashi T, Yano T, Sano K, Kugiyama K. Adiopnectin is released from the heart in patients with heart failure. Int J Cardiol 2009; 132 (2): 221-226.

35. Haugenb E, Furukawa Y, Isicab A, Fuab M. Increased Adiponectin Level in parallel with increased NT-Pro BNP in patients with sever heart failure in the elderly: A hospital cohort study 2008; 2: 216-219.

Received September 5, 2011. Accepted November 30, 2011. 